\title{
Clinical value of thalidomide on kk-rat model through TNF-a mediated inflammation approach
}

\author{
Min HUANG ${ }^{1,2 *}$, Jie DUAN", Bin YU ${ }^{4 *}$ (D), Si-lin ZHENG ${ }^{2}$, Qi CHEN², Fei LIN ${ }^{5}$, Nan ZENG ${ }^{6}$, Bao-dong LING $^{7}$
}

\begin{abstract}
To observe the influence of thalidomide on tumor necrosis factor-a (TNF- $\alpha$ ) of spontaneous type-2 diabetes rat (kk-Ay rat) model, and to explore the clinical value of TNF-a mediated inflammation approach to improve the injury on epithelial cell of kidney tubules. There are $30 \mathrm{kk}$-Ay rates being chosen to establish the Diabetic Nephropathy model and divided into thalidomide group and the model control group, 15 pieces for each group respectively. The levels of TNF- $\alpha$, IL-1 $\beta$, interleukin - 6 (IL-6) and interleukin -18 (IL-18) of kk-Ay in the thalidomide group and the model control group were both at a higher level before treatment, but the difference was not statistically significant $(\mathrm{P}>0.05)$; The levels of TNF- $\alpha$, IL-1 $\beta$, interleukin -6 (IL-6) and interleukin -18 (IL-18) in kk-Ay rats 8/10/12 weeks after the treatment in the thalidomide group were significantly decreased, with statistically significant differences compared with the model control group $(\mathrm{P}<0.05)$. The histopathological changes of kidney tubules epithelial cell injury on rats were observed through dissection. Thalidomide will effectively lower TNF- $\alpha$ and IL$1 \beta$ expression levels in kk-Ay rat models, reduce inflammatory response, and thus improve damage on kidney tubules epithelial cell, which is worthy of further exploration and application.
\end{abstract}

Keywords: thalidomide; tucorrelation mor necrosis factor $-\alpha$; interleukin-1 $\beta$; kidney tubules epithelial cell.

Practical Application: Inhibition of inflammatory response by thalidomide in kk-Ay rat.

\section{Introduction}

Diabetes is a chronic noncommunicable disease. Clinically, the disease caused by pancreatic b cell damage is called type-1 diabetes, while type-2 diabetes (Binker-Cosen et al., 2017) occurs when the body produces insulin which cannot be used by cells. With the improvement of people's living standards and the change of diet structure, the incidence of diabetes is on the rise globally (Liu et al., 2017a). The epidemiological survey in China shows that the incidence of diabetes on people over 20 years old is about $9.7 \%$, among which over $90 \%$ are type- 2 diabetes, and $20 \%-40 \%$ of patients are complicated with diabetic nephropathy (Arulkumaran et al., 2017). Diabetic nephropathy, mainly characterized by proteinuria and hypertension, is a common chronic complication of diabetes and serves as an important cause of end-stage nephropathy (Lei et al., 2018). It has been reported that deaths caused by diabetic nephropathy account for about $60 \%$ of total diabetes-related deaths (Bondeva et al., 2018).

The existing studies suggest that the pathological mechanism of diabetic nephropathy is related to abnormal glucose metabolism pathway, changes in kidney hemodynamics, cytokines, inflammatory responses and genetic susceptibility factors and etc, and more and more scholars agree on the inflammatory response theory (Zhang et al., 2018; Dionísio et al., 2020a, b; Grom et al., 2020; Wu et al., 2020). As a natural focal disease, diabetes is accompanied by an obvious inflammatory response, which plays a crucial role in microvascular complications such as diabetic nephropathy, which has been verified in previous laboratory studies (Lovshin et al., 2017). In this study, $30 \mathrm{kk}-A y$ rat models were used as experimental animals to further explore the clinical value of thalidomide in improving the damage on kidney tubules epithelial cell through TNF- $a$ mediated inflammatory pathways.

\section{Materials and methods}

\subsection{General data}

The study was carried out since Aug 2019 till Jun 2020, under the principle of good laboratory animal care. The project was approved by the ethics committee of Mianyang Central Hospital for care and use of laboratory animals. The flow chart of the experiment was shown in Figure 1.

Received 22 Feb., 2021

Accepted 10 Mar., 2021

${ }^{1}$ Department of Respiratory and Critical Care Medicine, The Affiliated Hospital of Southwest Medical University, Luzhou, China

${ }^{2}$ Nuring Department, The Affiliated Hospital of Southwest Medical University, Luzhou, China

${ }^{3}$ Department of Pharmacy, The 3rd Affiliated Hospital Of Chengdu Medical College, Pidu District People's Hospital, Chengdu, Chengdu, China

${ }^{4}$ Department of Pharmacy, Mianyang Central Hospital, Mianyang, China

${ }^{5}$ Department of Pharmacy, Clinical Medical College and The First Affiliated Hospital of Chengdu Medical College, Chengdu, China

${ }^{6}$ School of Pharmacy, Chengdu University of Traditional Chinese Medicine, Chengdu, China

${ }^{7}$ Sichuan Province College Key Laboratory of Structure-Specific Small Molecule Drugs, School of Pharmacy, Chengdu Medical College, Chengdu, China

*Corresponding author: binyu3223@yeah.net

"Min Huang and Jie Duan are the co-first authors. 


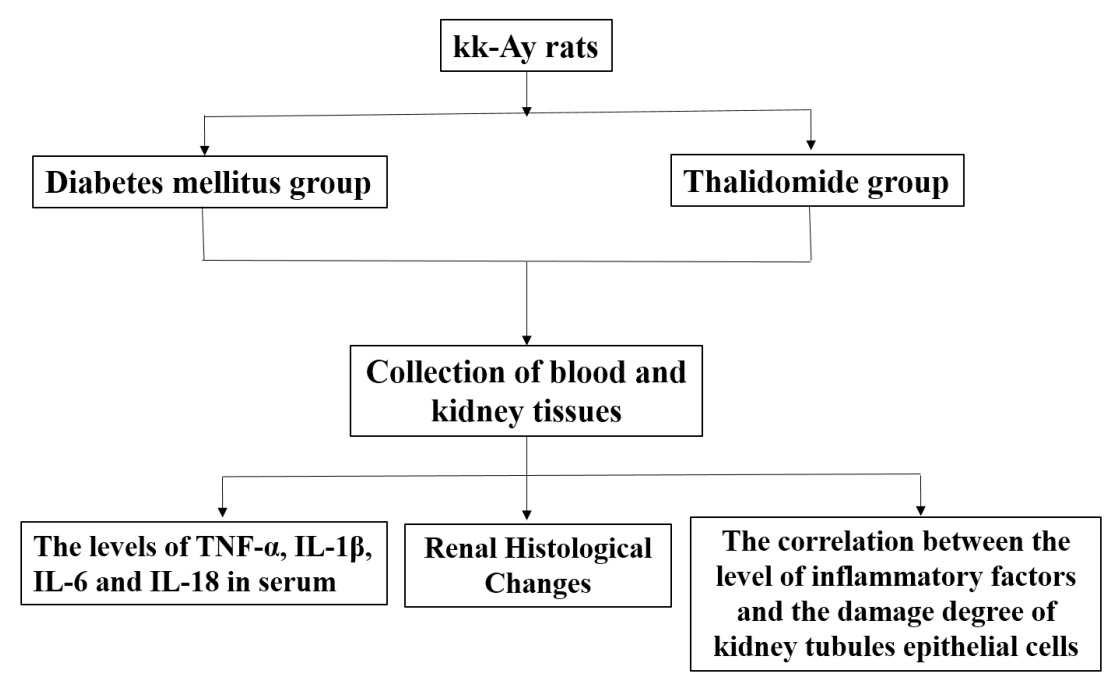

Figure 1. The flow chart of the experiment.

The experimental animals were 30 8-week-old kk-Ay rats from the institute of zoology, Chinese Academy of Medical Sciences. The diabetic nephropathy model was established. All rats were kept in cages during the study and given a high-fat and high-sugar diet. There're $30 \mathrm{kk}$ rates divided into thalidomide group and the model control group, 15 pieces for each group respectively. The diabetic nephropathy model was established. The average body mass of the thalidomide group was $(41.25 \pm 5.94) \mathrm{g}$; the average body mass of the model control group was $(40.89 \pm 6.11)$ $\mathrm{g}$. There is no statistical significance between the two groups $(\mathrm{P}>0.05)$, which is comparable.

\subsection{Research method}

Model control group: during the study, kk-Ay rats were given the same feeding conditions as the thalidomide group, with no drug intervention and treatment.

Thalidomide group: the kk-Ay rates were given the drug by gavage, the thalidomide were purchased from Jiangsu Changzhou Pharmaceutical Factory Co., Ltd., approval No.: GYZZ H32026129, specification: $25 \mathrm{mg}$, dosage calculated subject to the body mass of rats: $200 \mathrm{mg} / \mathrm{kg} / \mathrm{d}$, grinded into powder and added 2-4 mL normal saline irrigation, continuous treatment for 12 weeks.

\subsection{Evaluation index}

(1) Observation index: the blood was taken through cardiac puncture for kk-Ay rats of the two groups. After centrifugation, the supernate was taken to detect the expression levels of tumor necrosis factor- $\alpha$ (TNF- $\alpha$ ), interleukin- $1 \beta$ rat (IL- $1 \beta)$, interleukin -6 (IL-6) and interleukin -18 (IL-18) at different time points before and $8 / 10 / 12$ weeks after the treatment. The kit was purchased from Jiangsu Jingmei Biotechnology Co., Ltd.

(2) Histopathology: put to death in rats after treatment, produce the pathological section of kidney tubules epithelial cell through dissection and observe the pathologic change of kidney tubules epithelial cell under a microscop, set the scoring criteria (Xu et al., 2017): normal (0 point), very few inflammatory cells infiltration or (and) slight edema (1 point), mild infiltration
(2 points), medium infiltration (3 points), obvious infiltration (4 points) and severe infiltration ( 5 points).

The kidney tissue cells of rats were extracted, the phosphate buffer was resuspended to adjust the concentration, and centrifugated at $2000 \mathrm{r} / \mathrm{min}$ for $5 \mathrm{~min}$. The supernatant was removed, then washed with phosphate buffer, and 7 amino actinomycin $\mathrm{D}$ was added. The renal cell apoptosis rate was detected by flow cytometry.

(3) Correlation analysis: Logistic regression analysis was used to analyze the correlation between the level of inflammatory factors and the damage degree of kidney tubules epithelial cells in rats.

\subsection{Statistical methods}

The data obtained from the study were statistically processed by SPSS 20.0 software. The measurement data were expressed as mean \pm standard deviation $(\mathrm{x} \pm \mathrm{s}$ ). The counting data were expressed as percentage $(\%)$, and the intergroup was tested by $x^{2}$. Rank sum test was used for grade data. The correlation study was analyzed by Logistic regression analysis. $\mathrm{P}<0.05$ was set as statistically significant.

\section{Results}

\subsection{TNF- $\alpha$ expression levels of two groups of serum before/ after treatment}

The serum TNF- $\alpha$ levels of kk rat in the thalidomide group and the model control group were both at a higher level before treatment, but there was no significant difference between the groups $(\mathrm{P}>0.05)$. The levels of TNF- $\alpha$ in kk-Ay rat in the thalidomide group were continuously down-regulated 8/10/12 weeks after treatment, with statistically significant differences compared with the model control group $(\mathrm{P}<0.05)$. Refer Table 1 for details.

\subsection{IL-1 $\beta, I L-6$ and IL-18 expression levels of two groups of serum before/after treatment}

(1) The serum IL-1 $\beta$ levels of kk-Ay rat in the two groups were both at a higher level before treatment, but there was no 
significant difference between the groups $(\mathrm{P}>0.05)$. The levels of IL- $1 \beta$ in kk rat in the thalidomide group were continuously down-regulated 8/10/12 weeks after treatment, with statistically significant differences compared with the model control group $(\mathrm{P}<0.05)$. Refer Table 2 for details;

(2) The serum IL-6 levels of kk-Ay rat in the two groups were both at a higher level before treatment, but there was no significant difference between the groups $(\mathrm{P}>0.05)$. The levels of IL-6 in kk rat in the thalidomide group were continuously down-regulated 8/10/12 weeks after treatment, with statistically significant differences compared with the model control group $(\mathrm{P}<0.05)$. Refer Table 3 for details;

(3) The serum IL-18 levels of kk-Ay rat in the two groups were both at a higher level before treatment, but there was no significant difference between the groups $(\mathrm{P}>0.05)$. The levels of IL-18 in kk rat in the thalidomide group were continuously down-regulated 8/10/12 weeks after treatment, with statistically significant differences compared with the model control group $(\mathrm{P}<0.05)$. Refer Table 4 for details.

\subsection{Histopathological changes of kidney tubules epithelial cells in rat}

Tissue samples were observed after staining. In the model control group, kidney tubules necrosis was observed, and the infiltration range of inflammatory cells was larger and the degree of inflammatory infiltration was more serious. In the thalidomide group, inflammation was significantly improved, and the degree of pathological damage and endothelial cell swelling was less. There was a statistically significant difference between the two groups $(\mathrm{P}<0.05)$. The histopathological scores are shown in Table 5 .

Table 1. TNF- $\alpha$ Expression Levels of Serum of the Two Groups of kk Rats before/after Treatment ( $\pm \mathrm{s}, \mathrm{pg} / \mathrm{mL})$.

\begin{tabular}{|c|c|c|c|c|c|}
\hline Group & Cases & Before Treatment & 7d after Treatment & 14d after Treatment & 21d after Treatment \\
\hline Thalidomide group & 15 & $29.82 \pm 7.61$ & $18.34 \pm 7.43^{*}$ & $12.20 \pm 7.52^{*}$ & $4.59 \pm 2.67^{\star}$ \\
\hline Model control group & 15 & $29.58 \pm 7.83$ & $30.05 \pm 8.54$ & $29.86 \pm 7.35$ & $29.97 \pm 5.46$ \\
\hline $\mathrm{t}$ value & & 0.085 & 4.007 & 6.505 & 16.173 \\
\hline $\mathrm{P}$ & & 0.933 & 0.001 & 0.001 & 0.001 \\
\hline
\end{tabular}

Notes: compared with that before treatment. ${ }^{*} \mathrm{P}<0.05$

Table 2. IL-1 $\beta$ Expression Levels of Serum of the Two Groups of kk Rats before/after Treatment (x \pm s, pg/mL).

\begin{tabular}{lccccc}
\hline Group & Cases & Before Treatment & 7d after Treatment & $14 \mathrm{~d}$ after Treatment & 21d after Treatment \\
\hline Thalidomide group & 15 & $15.84 \pm 0.98$ & $14.62 \pm 0.73$ & $14.13 \pm 0.56^{*}$ & $13.22 \pm 0.18^{*}$ \\
Model control group & 15 & $15.79 \pm 0.97$ & $15.80 \pm 0.92$ & $15.74 \pm 0.67$ & $15.84 \pm 0.63$ \\
$\mathrm{~T}$ & & 0.140 & 3.891 & 7.141 & 15.487 \\
$\mathrm{P}$ & & 0.889 & 0.001 & 0.001 & 0.001 \\
\hline
\end{tabular}

Notes: compared with that before treatment. ${ }^{\star} \mathrm{P}<0.05$.

Table 3. IL-6 Expression Levels of Serum of the Two Groups of kk Rats before/after Treatment ( \pm \pm s, pg/mL).

\begin{tabular}{lccccc}
\hline Group & Cases & Before Treatment & 7d after Treatment & $14 \mathrm{~d}$ after Treatment & 21d after Treatment \\
\hline Thalidomide group & 15 & $110.24 \pm 9.88$ & $78.45 \pm 8.52^{*}$ & $75.14 \pm 7.96^{*}$ & $71.03 \pm 6.28^{*}$ \\
Model control group & 15 & $110.12 \pm 9.76$ & $108.92 \pm 9.63$ & $109.22 \pm 9.58$ & $107.34 \pm 8.97$ \\
$\mathrm{t}$ & & 0.034 & 9.178 & 10.597 & 12.843 \\
$\mathrm{P}$ & & 0.974 & 0.001 & 0.001 & 0.001 \\
\hline
\end{tabular}

Notes: compared with that before treatment. ${ }^{*} \mathrm{P}<0.05$.

Table 4. IL-18 Expression Levels of Serum of the Two Groups of kk Rats before/after Treatment ( \pm s, pg/mL).

\begin{tabular}{lccccc}
\hline Group & Cases & Before Treatment & 7d after Treatment & 14d after Treatment & 21d after Treatment \\
\hline Thalidomide group & 15 & $75.54 \pm 7.89$ & $69.23 \pm 8.06$ & $67.33 \pm 8.12$ & $63.17 \pm 4.59$ \\
Model control group & 15 & $75.25 \pm 7.91$ & $75.64 \pm 9.35$ & $80.27 \pm 9.46$ & $72.58 \pm 7.83$ \\
$\mathrm{t}$ & & 0.101 & 2.011 & 4.020 & 4.015 \\
$\mathrm{P}$ & & 0.921 & 0.054 & 0.001 & 0.001 \\
\hline
\end{tabular}

Notes: compared with that before treatment. ${ }^{\star} \mathrm{P}<0.05$.

Table 5. Histopathological Scores of Renal Tubular Epithelial Cell Injury in two Groups of Rats [n (\%) ].

\begin{tabular}{lccccc}
\hline Group & Cases & 0 Point & $1-2$ Points & $3-4$ Points & 5 Points \\
\hline Thalidomide group & 15 & $12(80.00)$ & $2(13.33)$ & $1(6.67)$ & $0(0.00)$ \\
Model control group & 15 & $0(0.00)$ & $0(0.00)$ & $12(80.00)$ & $3(20.00)$ \\
Z & & & 26.308 & \\
P & & & 0.001 & \\
\hline
\end{tabular}


The apoptosis rate of $\mathrm{kk}$ rat renal cells in the thalidomide group was lower than that in the model control group, and the difference between the groups was statistically significant $(\mathrm{P}<0.05)$. See Figure 2 for details.

\subsection{Correlation between TNF- $\alpha$ level and epithelial cell injury of renal tubules}

The Logistic regression analysis showed that serum TNF- $\alpha$ level was correlated with the degree of damage of renal tubular epithelial cells in kk-Ay rat, and the higher TNF- $\alpha$ level was, the more serious the damage was $(\mathrm{P}<0.05)$. Refer Table 6 and Figure 3 for details.

\section{Discussions}

Diabetic nephropathy is one of the serious chronic microvascular complications of diabetes. The failure to receive timely and effective treatment and intervention will further lead to end-stage renal failure and even death of patients, which is clinically complicated and difficult to treat and etc. (Becchi et al., 2017). The onset of diabetes shall be regarded as the initial of diabetic nephropathy, and the detailed pathogenesis has not been elucidated fully yet. However, the previous studies suggest that renal hemodynamic changes, abnormal fat and glucose metabolism functions, genetic factors, and inflammatory responses are related to it to some extent (Li et al., 2018). Hypertension, proteinuria, low glomerular filtration rate and nephrotic syndrome are the main clinical manifestations of this disease. The active symptomatic treatment and intervention measures to be taken at the early stage will delay the progress of the disease effectively, help to reduce the incidence of end-stage nephropathy and renal failure, and decrease the risk of death. Diabetes mellitus is a focal inflammatory disease caused by metabolic disorders, and the progression of the disease is accompanied by inflammatory response, so more and more scholars believe that inflammatory response is closely related to the occurrence of diabetic nephropathy. Inflammatory response is a complex disease resistance response occurring in the entire tissues and multiple organs, and its essence is the process of inflammatory factors fighting against the body. Patients may show body fever and leukocytosis, which play a crucial role in diabetic microvascular complications.

The angiotensin-II receptor antagonist medication is usually taken clinically for diabetic nephropathy in early stage, which has certain effect in delaying the process of renal fibrosis and reducing the incidence of cardiovascular adverse events (Sung et al., 2017). In this study, diabetic nephropathy model was established in kk-Ay rat and treated with thalidomide. This product is a glutamic acid derivative, which has been reported to have a good therapeutic effect on neuralgia, joint pain, fever, lymph node enlargement and other inflammatory reactions or diseases, and has anti-angiogenesis, anti-tumor and immunomodulatory effects. It will stabilize lysosomal membrane by inhibiting chemotaxis of neutrophils. In addition, thalidomide has the structure of piperidine ring, so it may act as the forebrain sleep center to have a sedative and antipruritic effect. Studies by scholars (Jeong et al., 2018) have confirmed that thalidomide can inhibit the synthesis of vascular endothelial growth factor (VEGF) and TNF- $\alpha$ at the molecular level, and inhibit stimulating cytokines and angiogenesis. As the immunomodulatory drugs, thalidomide regulates the immune state of the body by regulating the secretion of cytokines, which can lower the level of cell adhesion factor and reduce the extravasation of white blood cells, thereby reducing the formation of the surface integrin subunit of white blood cells, and inhibiting the migration and adhesion

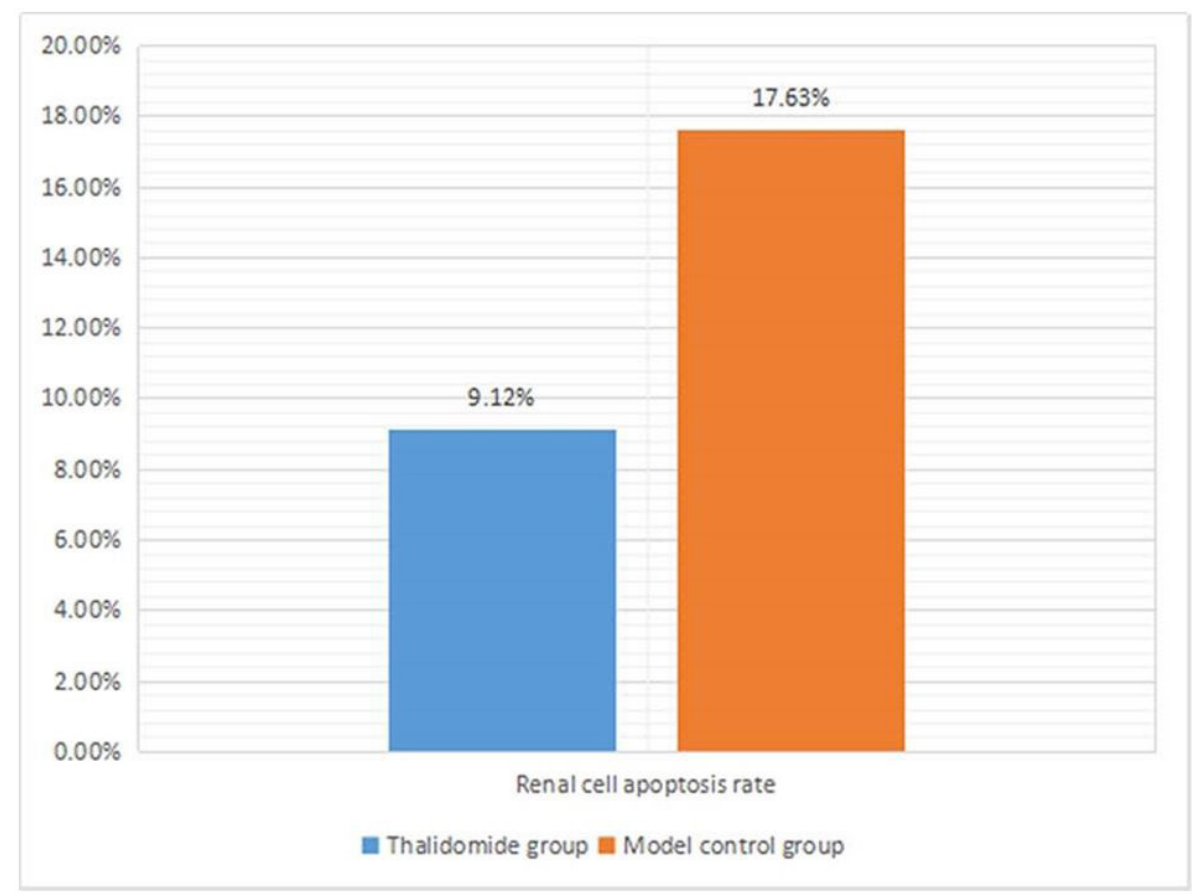

Figure 2. Apoptosis Rate of kk Rat Renal Cells in Thalidomide Group and Model Control Group. 
Table 6. Logistic Regression Analysis on TNF- $\alpha$ Level and Epithelial Cell Injury of Renal Tubules.

\begin{tabular}{cccccc}
\hline Variable & Coefficient & Standard Deviation & Wald Statistic & Degrees of Freedom & Significance Level \\
\hline TNF- $\alpha$ level & 2.206 & 1.005 & 4.832 & 1 & 0.021 \\
\hline
\end{tabular}
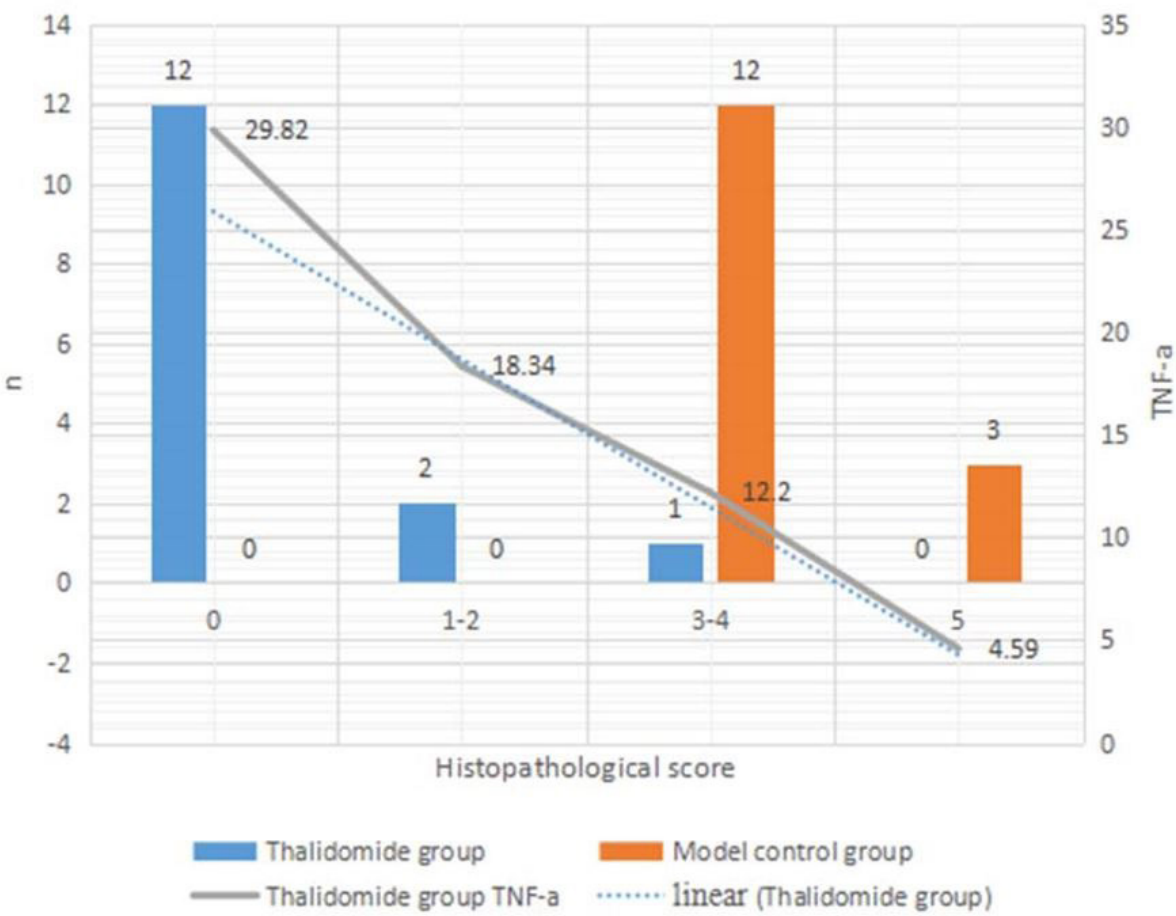

Figure 3. Correlation between TNF- $\alpha$ Level and Epithelial Cell Injury of Renal Tubules in kk Rats.

mechanism of white blood cells. Therefore, it has a significant effect on reducing the inflammatory response.

In this study, serum TNF- $\alpha$, IL- $1 \beta$, IL- 6 and IL-18 levels of $\mathrm{kk}$-Ay rats in the thalidomide group decreased significantly after treatment, with statistically significant differences compared with the model control group, suggesting that the use of thalidomide will improve renal inflammatory symptoms effectively in $\mathrm{kk}$-Ay rats. It was found through the observation on histopathological specimens after staining that the inflammatory infiltration range and degree of kk rat renal tubular epithelial cells in the thalidomide group were lighter than that in the model control group, with significantly reduced neovascularization, suggesting that thalidomide has a good inhibitory effect on inflammatory response and neovascularization. The relevant studies of Zhu et al. (2017) showed that the mechanism of anti-angiogenesis of thalidomide may be due to the blocking effect of its metabolites on the activation of VEGF and fibroblast growth factor (bFGF), which mediate angiogenesis. Practice has proved that infectious and non-infectious stimulation in vitro and vivo will activate inflammatory mechanisms in the body, induce some protease molecule activation after activation, resulting in processing and secretion of proinflammatory cytokines, such as TNF- $\alpha$, IL-1 $\beta$, IL-6 and IL-18 and etc., participate in natural immune response. It's closely related to the reaction process of all kinds of acute or chronic inflammatory reaction, as we as the occurrence and development of many kinds of diseases. The above factors are the main contents of TLR4, myd88 and nf- $\mathrm{kb}$ and co-exist in the serum of diabetic nephropathy rat, and their expression levels increase significantly in the active stage of the disease. As inflammatory markers, they can synergistically mediate inflammatory response, damage of renal tubular epithelial cells, and activate cells to secrete other inflammatory mediators, thereby aggravating inflammatory response. The studies of Hong et al. (2017). showed that thalidomide inhibited the expression of TLR4, myd88 and $\mathrm{nf}-\mathrm{kb}$ proteins in proximal renal tubular epithelial cells of high-glucose rat, while the inhibition of TLR4 enhanced the anti-inflammatory effect of thalidomide. TLR4 is the main receptor for the natural immune system to recognize pathogenic microorganisms. This signaling pathway is activated by lipopolysaccharide stimulation. The activated TLR 4 and myd 88 co-domain binding will induce the release of a large number of pro-inflammatory cytokines, thus playing an immune response role. It plays an important role in occurrence, development and prognosis of related diseases caused by infectious diseases and bacteria-free inflammation. In this study, the apoptosis rate of kk-Ay rat renal cells in the thalidomide group was significantly lower than that in the model control group, which also indicated that the damage of renal tubular epithelial cells in kk mouse was reduced. The studies of Ma et al. (2017). also showed that thalidomide had a good therapeutic effect on the inflammatory disease erythematous leprosy, and would reduce the level of serum TNF- $\alpha$, which was mainly related to the significant inhibition of monocytes and macrophages' secretion 
of TNF- $\alpha$ and the reduction of inflammatory response of the body. Du et al. (2017). conducted laboratory studies on rats with collagen-induced arthritis, and the results also showed that thalidomide could reduce the serum level of TNF- $\alpha$, and suggested that the expression level of TNF- $\alpha$ might be related to the dose of thalidomide.

It was concluded from the studies of Maimaiti Yisireyili et al. (2017). that the dose of thalidomide at $200 \mathrm{mg} / \mathrm{kg} / \mathrm{d}$ could reduce inflammation significantly in the rat model, so thalidomide was also selected as the experimental dose in this study. The Logistic regression analysis show that the serum level of TNF- $\alpha$ and the damage level of kk-Ay rat renal tubular epithelial cell have a certain correlation, and the higher the level of TNF- $\alpha$ renal tubular epithelial cells in mice, the more serious the damage degree. The inflammatory factor levels in other cells are increased due to the release of large amounts of TNF- $\alpha$. The TNF- $\alpha$ mediated inflammatory reaction is an important performance of diabetic kidney disease progress, and the aggravation of illness means the damage of $\mathrm{kk}$ rat renal tubular epithelial cell is aggravated. Thus, the use of thalidomide to reduce serum TNF- $\alpha$, IL- $1 \beta$, IL-6 and IL-18 levels in kk-Ay rat is mainly aimed at improving renal tubular epithelial cell damage by acting on TNF- $\alpha$ mediated inflammatory pathways. Yunlong Liu et al. (2017b). proposed in previous studies that thalidomide could treat rats suffering diabetic nephropathy by lowering kidney/body mass index, protecting renal cells, reducing inflammatory response and renal cell damage and etc. mechanism.

\section{Conclusion}

The application of thalidomide to kk-Ay rat model shall down-regulate the expression levels of serum TNF- $\alpha$ and IL- $1 \beta$ effectively, reduce inflammatory response, and thus improve the damage of renal tubular epithelial cells, which has the value of further exploration in clinical application.

\section{Acknowledgements}

This work was supported by Scientific Research Subject of Health Commission of Sichuan Province (18PJ540); Hypertension Disease (Taige) Special Scientific Research Project of Sichuan Medical Association (2019TG28).

\section{References}

Arulkumaran, N., Sixma, M. L., Jentho, E., Ceravola, E., Bass, P. S., Kellum, J. A., Unwin, R. J., Tam, F. W. K., \& Singer, M. (2017). Sequential analysis of a panel of biomarkers and pathologic findings in a resuscitated rat model of sepsis and recovery. Critical Care Medicine, 45(8), e821. http://dx.doi.org/10.1097/CCM.0000000000002381. PMid:28430696.

Becchi, S., Buson, A., Foot, J., Jarolimek, W., \& Balleine, B. W. (2017). Inhibition of semicarbazide-sensitive amine oxidase/vascular adhesion protein-1 reduces lipopolysaccharide-induced neuroinflammation. British Journal of Pharmacology, 174(14), 2302-2317. http://dx.doi. org/10.1111/bph.13832. PMid:28437839.

Binker-Cosen, M. J., Richards, D., Oliver, B., Gaisano, H. Y., Binker, M. G., \& Cosen-Binker, L. I. (2017). Palmitic acid increases invasiveness of pancreatic cancer cells AsPC-1 through TLR4/ROS/NF- $\kappa \mathrm{B} /$
MMP-9 signaling pathway. Biochemical and Biophysical Research Communications, 484(1), 152-158. http://dx.doi.org/10.1016/j. bbrc.2017.01.051. PMid:28088520.

Bondeva, T., Schindler, C., Schindler, K., \& Wolf, G. (2018). MORG1+/mice are protected from histological renal damage and inflammation in a murine model of endotoxemia. BMC Nephrology, 19(1), 29. http://dx.doi.org/10.1186/s12882-018-0826-4. PMid:29402223.

Dionísio, A. P., Carvalho-Silva, L. B., Vieira, N. M., Wurlitzer, N. J., Pereira, A. C. S., Borges, M. F., Garruti, D. S., \& Araújo, I. S. (2020a). Antioxidant and prebiotic effects of a beverage composed by tropical fruits and yacon in alloxan-induced diabetic rats. Food Science and Technology, 40(1), 202-208. http://dx.doi. org/10.1590/fst.34518.

Dionísio, A. P., Silva, M. F. G., Carioca, A. A. F., Adriano, L. S., Abreu, F. A. P., Wurlitzer, N. J., Pinto, C. O., \& Pontes, D. F. (2020b). Effect of yacon syrup on blood lipid, glucose and metabolic endotoxemia in healthy subjects: a randomized, double-blind, placebo-controlled pilot trial. Food Science and Technology, 40(1), 194-201. http://dx.doi. org/10.1590/fst.38218.

Du, C., Zhang, T., Xiao, X., Shi, Y. H., Duan, H. J., \& Ren, Y. Z. (2017) Protease-Activated Receptor-2 promotes kidney tubular epithelial inflammation by inhibiting autophagy via the PI3K/Akt/mTOR signalling pathway. The Biochemical Journal, 474(16), 2733-2747. http://dx.doi.org/10.1042/BCJ20170272. PMid:28694352.

Grom, L. C., Rocha, R. S., Balthazar, C. F., Guimarães, J. T., Coutinho, N. M., Barros, C. P., Pimentel, T. C., Venâncio, E. L., Collopy, I. Jr., Maciel, P. M. C., Silva, P. H. F., Granato, D., Freitas, M. Q., Esmerino, E. A., Silva, M. C., \& Cruz, A. G. (2020). Postprandial glycemia in healthy subjects: Which probiotic dairy food is more adequate? Journal of Dairy Science, 103(2), 1110-1119. http://dx.doi.org/10.3168/ jds.2019-17401. PMid:31785881.

Hong, Y. A., Yang, K. J., Jung, S. Y., Chang, Y. K., Park, C. W., Yang, C. W., Kim, S. Y., \& Hwang, H. S. (2017). Paricalcitol attenuates lipopolysaccharide-induced inflammation and apoptosis in proximal tubular cells through the prostaglandin E2receptor EP4. Kidney Research and Clinical Practice, 36(2), 145-158. http://dx.doi.org/10.23876/j.krcp.2017.36.2.145. PMid:28680822.

Jeong, B. Y., Park, S. R., Cho, S. K., Yu, S. L., Lee, H. Y., Park, C. G., Kang, J. K., Jung, D. Y., Park, M. H., Hwang, W. M., Yun, S. R., Jung, J. Y., \& Yoon, S. H. (2018). TGF- $\beta$-mediated NADPH oxidase 4-dependent oxidative stress promotes colistin-induced acute kidney injury. The Journal of Antimicrobial Chemotherapy, 73(4), 962-972. http://dx.doi.org/10.1093/jac/dkx479. PMid:29329393.

Lei, R., Zhao, F., Tang, C. Y., Luo, M., Yang, S. K., Cheng, W., Li, X. W., \& Duan, S. B. (2018). Mitophagy plays a protective role in iodinated contrast-induced acute renal tubular epithelial cells injury. Cellular Physiology \& Biochemistry: International Journal of Experimental Cellular Physiology Biochemistry \& Pharmacology, 46(3), 975-985. http://dx.doi.org/10.1159/000488827. PMid:29680838.

Li, W. N., Han, H., Jing, Z. Y., Yang, X. H., Zhang, Y., \& Wei, J. L. (2018). Mitochondrial oxidative damage and apoptosis induced by high glucose through Rho kinase signal pathway in renal tubular epithelial cells. Asian Pacific Journal of Tropical Medicine, 11(6), 399. http://dx.doi.org/10.4103/1995-7645.234769.

Liu, H. F., Xiong, J. C., He, T., Xiao, T. L., Li, Y., Yu, Y. L., Huang, Y. H., Xu, X. L., Huang, Y. J., Zhang, J. B., Zhang, B., \& Zhao, J. H. (2017a). High uric acid-induced epithelial-mesenchymal transition of renal tubular epithelial cells via the TLR4/NF-kB signaling pathway. American Journal of Nephrology, 46(4), 333-342. http://dx.doi. org/10.1159/000481668. PMid:29017152. 
Liu, Y. L., Li, D. R., He, Z. Q., Liu, Q., Wu, J. H., Guan, X. F., Tao, Z. W., \& Deng, Y. L. (2017b). Inhibition of autophagy-attenuated calcium oxalate crystal-induced renal tubular epithelial cell injury in vivo and in vitro. Oncotarget, 9(4), 4571-4582. http://dx.doi. org/10.18632/oncotarget.23383. PMid:29435125.

Lovshin, J. A., Rajasekeran, H., Lytvyn, Y., Lovblom, L. E., Khan, S., Alemu, R., Locke, A., Lai, V., He, H., Hittle, L., Wang, W., Drucker, D. J., \& Cherney, D. Z. I. (2017). Dipeptidyl peptidase 4 inhibition stimulates distal tubular natriuresis and increases in circulating SDF-1 $\alpha^{1-67}$ in patients with type 2 diabetes. Diabetes Care, 40(8), 1073-1081. http://dx.doi.org/10.2337/dc17-0061. PMid:28550195.

Ma, L., Ni, H., Zou, X., Yuan, Y. Y., Luo, C., Liu, B. Y., Wang, F. Y., Xi, Y., Chu, Y. D., Xu, P. J., Qiu, X. H., Li, S., \& Bu, S. Z. (2017). Mori cortex prevents kidney damage through inhibiting expression of inflammatory factors in the glomerulus in streptozocin-induced diabetic rats. Iranian Journal of Basic Medical Sciences., 20(6), 715-721. PMid:28868127.

Sung, P. H., Chiang, H. J., Wallace, C. G., Yang, C. C., Chen, Y. T., Chen, K. H., Chen, C. H., Shao, P. L., Chen, Y. L., Chua, S., Chai, H. T., Chen, Y. L., Huang, T. H., Yip, H. K., \& Lee, M. S. (2017). Exendin-4-assisted adipose derived mesenchymal stem cell therapy protects renal function against co-existing acute kidney ischemiareperfusion injury and severe sepsis syndrome in rat. American Journal of Translational Research, 9(7), 3167-3183. PMid:28804538.
Wu, L., Weng, M., Zheng, H., Lai, P., Tang, B., Chen, J., \& Li, Y. (2020). Hypoglycemic effect of okra aqueous extract on streptozotocininduced diabetic rats. Food Science and Technology, 40(4), 972-978. http://dx.doi.org/10.1590/fst.28619.

Xu, Y., Zhang, B., Xie, D., Hu, Y., Li, H. L., Zhong, L. L., Wang, H. W., Jiang, W., Ke, Z. P., \& Zheng, D. H. (2017). Nanoparticle-mediated dual delivery of resveratrol and DAP5 ameliorates kidney ischemia/reperfusion injury by inhibiting cell apoptosis and inflammation. Oncotarget, 8(24), 3954739558. http://dx.doi.org/10.18632/oncotarget.17135. PMid:28465474.

Yisireyili, M., Takeshita, K., Saito, S., Murohara, T., \& Niwa, T. (2017). Indole-3-propionic acid suppresses indoxyl sulfate-induced expression of fibrotic and inflammatory genes in proximal tubular cells. Nagoya Journal of Medical Science, 79(4), 477-486. PMid:29238104.

Zhang, W., Glaze, J. H., \& Wynne, D. (2018). Combined membranous nephropathy and tubulointerstitial nephritis as a rare renal manifestation of IgG4-related disease: a case-based literature review. CEN Case Reports, 7(1), 137-142. http://dx.doi.org/10.1007/s13730018-0311-8. PMid:29388171.

Zhu, F., Chong Lee Shin, O. L., Xu, H., Zhao, Z., Pei, G., Hu, Z., Yang, J., Guo, Y., Mou, J., Sun, J., Zhu, H., Wang, Y., Wang, M., Yang, Q., Liao, W., Xu, G., Zeng, R., \& Yao, Y. (2017). Melatonin promoted renal regeneration in folic acid-induced acute kidney injury via inhibiting nucleocytoplasmic translocation of HMGB1 in tubular epithelial cells. American Journal of Translational Research, 9(4), 1694-1707. PMid:28469775. 